\title{
Management of gastroesophageal reflux disease and hiatus hernia: Overview and authors' perspective
}

\author{
Corinne Owers ${ }^{*}$, Roger Ackroyd \\ Department of Upper GI Surgery, Sheffield Teaching Hospitals NHS Foundation Trust, Sheffield, South Yorkshire UK, S5 7AU
}

Email address:

corinneowers@doctors.org.uk(C. Owers),roger.ackroyd@sth.nhs.uk(R. Ackroyd)

\section{To cite this article:}

Corinne Owers, Roger Ackroyd. Management of Gastroesophageal Reflux Disease and Hiatus Hernia: Overview and Authors' Perspective. Journal of Surgery. Vol. 1, No. 4, 2013, pp. 51-58. doi: 10.11648/j.js.20130104.12

\begin{abstract}
Hiatus hernia and GORD is a common problem, with many different approaches to treatment. Management has changed dramatically over the years as new and varied treatments have become available. The treatment differs between countries depending on the availability of the various therapies. Overall, medical therapy is undoubtedly the commonest form of treatment, with surgery being used as second line therapy or for intractable symptoms. This paper provides an overview of reflux disease and the available treatments, as well as describing the most common surgical techniques, providing the practitioner with guidance as to when surgery may be a viable option.
\end{abstract}

Keywords: Gastro-Oesophageal Reflux, Management of Reflux Disease, Para-Oesophageal Hiatus Hernia

\section{Introduction}

The treatment of gastroesophageal reflux (GORD) and paraoesophageal hernia is complex, with no international consensus achieved (1). Ten to $20 \%$ of the western world's population suffers with GORD, although 2004 UK guidelines suggest this may be up to $40 \%$ (2).

Reflux occurs primarily during transient relaxation of the lower oesophageal sphincter (3). Symptoms include heartburn, cough (reflux of acid causing laryngeal spasm), shortness of breath (often secondary to aspiration) and unpleasant oral tastes.

Several factors are known to increase the risk of reflux, most notably obesity $(4,5)$, tobacco, alcohol intake (6) and hiatus hernia. It is important to note that the degree of symptomatic reflux does not always correlate with the level of oesophageal mucosal damage; endoscopy negative reflux (reflux symptoms in the absence of endoscopic signs) is more common than reflux oesophagitis.

The consequences of GORD can be substantial. Erosive oesophagitis occurs in approximately $45 \%$ of cases, oesophageal strictures in $8 \%$ and oesophageal ulcers in $6 \%$ (7). Barrett's oesophagus (columnar metaplasia of the oesophagus) occurs in approximately $1-2 \%$ of patients with GORD (8-11). Diagnosis is often made only when a patient presents with symptoms of oesophageal adenocarcinoma, and endoscopic examination is performed. The overall risk of developing adenocarcinoma in Barrett's oesophagus is approximately $0.5 \%$ (1)- 2.5 times higher in men than in women $(7,12)$. This may be in part due to the increased likelihood of abdominal obesity, and consequently intra-abdominal pressure, in male patients. The Gold standard method of diagnosis of GORD is $\mathrm{pH}$ and manometry testing.

Hiatus hernia can be caused by one or more of three mechanisms: widening of the diaphragmatic hiatus; oesophageal shortening causing the stomach to 'pull' through the hiatus; and increased intra-abdominal pressure causing a pressure effect forcing the stomach through the hiatus. Given that up to $80 \%$ of power athletes can be seen to have a hiatus hernia, this third cause may be significant (13). A congenital hiatus hernia, also known as a congenital diaphragmatic hernia, is a rare but potentially life-threatening form of hiatus hernia found in children. Although operative repair is often successful, development of a subsequent hiatus hernia is relatively common. This is considered to be due to slow pulmonary expansion, lung hypoplasia, and shortening of the abdominal oesophagus (14). Mechanism \& Types are mentioned, but what about the causes, especially congenital?

Two types of hiatus hernia exist: "sliding" $(95 \%)$ and 'rolling' (or paraoesophageal) hernia (5\%). In the former the upper stomach and lower oesophagus slide up into the chest, whilst in the latter the body of the stomach protrudes through the oesophageal hiatus to lie alongside the oesophagus, with no movement of the gastro-oesophageal junction. Also, with 
a paraoesophageal hernia, a true peritoneal hernia sac encloses the stomach, most commonly alongside the left diaphragmatic crus. They tend to become larger with time and incidence increases with age (see figure 1).

Two types of hiatus hernia exist: "sliding" (95\%) and 'rolling' (or paraoesophageal) hernia (5\%). In the former the upper stomach and lower oesophagus slide up into the chest, whilst in the latter the body of the stomach protrudes through the oesophageal hiatus to lie alongside the oesophagus, with no movement of the gastro-oesophageal junction. Also, with a paraoesophageal hernia, a true peritoneal hernia sac encloses the stomach, most commonly alongside the left diaphragmatic crus. They tend to become larger with time and incidence increases with age (see figure 1).

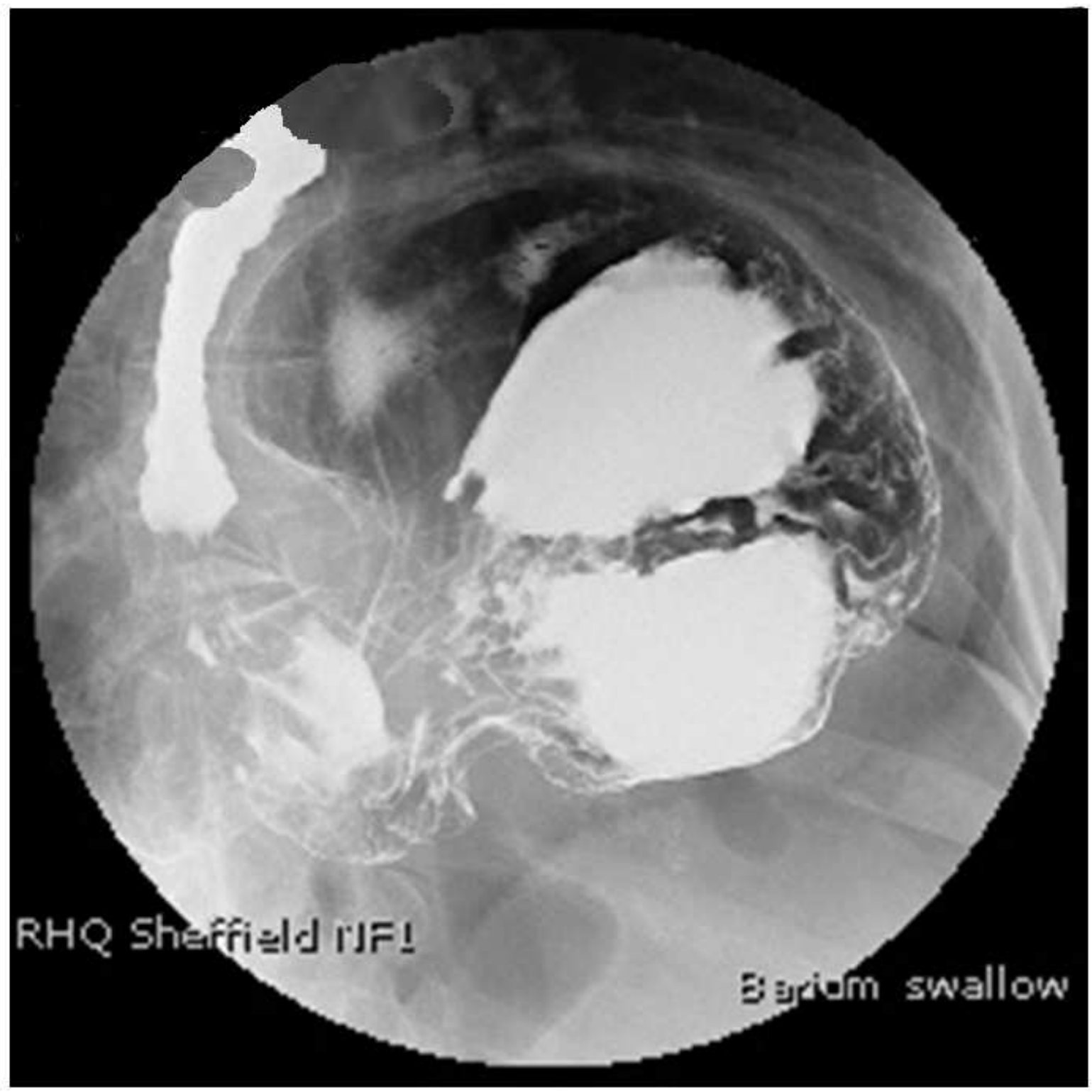

Figure 1. A barium swallow showing a large paraoesophageal hiatus hernia (Sheffield Teaching Hospitals)

A sliding hiatus hernia usually presents with heartburn or ENT symptoms, such as hoarse voice or nocturnal cough/wheeze. Up to $50 \%$ of patients with a paraoesophageal hernia may be asymptomatic (12); symptomatic patients may complain of epigastric fullness (83\%), post-prandial pain $(75 \%)$, regurgitation $(60 \%)$ and heartburn $(57 \%)$. A further $41 \%$ of patients experience nausea, vomiting and aspiration.

Serious consequences such as respiratory embarrassment and obstruction occur in $25 \%$ and $13 \%$ respectively (12). The anatomical abnormalities associated with the paraoesophageal hiatus hernia, such as decreased lower oesophageal sphincter length and pressure, and counteracting the anti-reflux effects of this diaphragmatic crus contribute to the increased likelihood of developing significant reflux. The hernia itself can act as a reservoir for gastric acid, which can then reflux into the oesophagus especially when swallowing or supine (15). The risk of strangulation and volvulus is greater with a paraoesophageal hernia, such that some surgeons advocate elective repair of this type of hiatus hernia (7). 


\section{Medical Therapies for Reflux}

Before the advent of modern medical therapies, many simple 'remedies' were advised such as not eating before sleep, elevating the head of the bed or sleeping propped up, and remedies such as drinking acidophilus milk or adding bicarbonate of soda to water. First line treatment of gastroesophageal reflux disease should be modification of lifestyle risk factors such as obesity, and oral intake. It has been demonstrated that cigarette smoking causes a decrease in lower oesophageal sphincter pressure, increasing reflux. A study examining the correlation between smoking and oesophageal $\mathrm{pH}$ with manometry demonstrated reflux during smoking in two-thirds of participants; one-third of all recorded reflux episodes throughout the study occurred whilst the subjects were smoking (16). Cessation may be the most successful method of treating GORD, although it may be difficult to persuade the patient to this effect. Significant alcohol consumption during early adulthood may increase the risk of reflux oesophagitis, although in older adults, there is disagreement about the exact correlation between alcohol and reflux (17). It has been suggested that wine may have a protective effect against the development of reflux oesophagitis and Barrett's oesophagus, as one study of the relationship between Barretts' reflux and adenocarcinoma with alcohol showed a decreased incidence of all 3 disorders in wine drinkers. The authors however, offered no suggestion as to any possible cause for this link (18)(What is the possible cause for the protective effect of wine?).

Medical therapies are successful in mild to moderate reflux but less so in severe cases (19). In 1975 ranitidine, a $\mathrm{H} 2$ receptor antagonist became a popular first line treatment (20), superseded in the 1990's by the proton-pump inhibitor (PPI) (20). This popular and effective treatment is widely used in the UK, with costs of $£ 425$ million in 2006. An estimated $£ 500$ million of NHS annual budget is spent unnecessarily on PPI's; the cheaper $\mathrm{H} 2$ antagonist class is only slightly less efficacious but significantly cheaper (21). A Cochrane review demonstrated the superior benefit of PPI as compared to $\mathrm{H} 2$ antagonists, but that these still have a superior effect to that of placebo in the treatment of reflux oesophagitis (22). Other pharmacological treatments of reflux include the use of baclofen, which may help to inhibit the transient relaxation of the sphincter (3). Medical treatments rarely if ever treat the underlying pathology and up to $80 \%$ of patients discontinuing PPI therapy relapse (23), as compared to only $32 \%$ of those taking ranitidine, suggesting that PPI's have a prophylactic effect.

Many cases of severe reflux may be linked to the presence or absence of H. Pylori, which is linked to chronic atrophic gastritis, an established precursor of gastric adenocarcinoma (24). The link between H. Pylori and reflux disease remains unproven and its presence may even have a protective effect against GORD (25). Although it is a known cause of gastritis and infects $50 \%$ of the world's population (26), gastritis is not always associated with reflux, and studies including a meta-analysis (27) published on the topic have shown a decreased risk of GORD in those individuals colonized by $\mathrm{H}$. Pylori (28).

\section{Endoscopic Management}

Diagnosis of GORD is usually made clinically based on symptoms, with empirical prescription of PPI's. Patients in whom this medical therapy is not effective often undergo endoscopy in order to diagnose oesophagitis, although the majority of patients have negative findings. Any diagnosis of Barrett's should be followed up with routine endoscopic surveillance.

Endoscopic treatment of symptomatic patients can usually be performed as a day case and is suitable in those unfit for surgery. It has demonstrated consistently good outcomes, including a $56 \%$ reduction in the need for medication (28-30).

Some new endoscopic techniques have been developed in the treatment of reflux. Endoscopic radio frequency thermal ablation (the Stretta procedure), which causes scarring at the lower oesophageal sphincter (LOS), thereby increasing sphincter pressure and decreasing reflux, was described as early as 2001 and UK guidelines advocated its use in 2009 (31). Originally pioneered as a treatment for Barrett's oesophagus, it has been found to be effective in the early stages for patients with resistant reflux. Endoscopic suturing of the lower oesophageal sphincter (plication) alters the anatomy of the LOS by increasing the angle of His. EndoCinch $^{\mathrm{TM}}$, Plicator ${ }^{\mathrm{TM}}$, Esophy $\mathrm{X}^{\mathrm{TM}}$, technologies designed in 2001, 2003 and 2007 respectively make endoscopic suturing less technically demanding. Plication can be submucosal or full thickness. One randomized controlled trial comparing endoscopic suturing of the LOS has also demonstrated short term-benefits, although long-term effects are yet to be proven (32). The injection of biocompatible polymers into the deep muscle or the submucosal layers of the cardia, increasing LOS pressure can also be used and the UK issued guidance in 2004 on its application. It reports evidence that at 12 months $67 \%$ of 85 patients involved in a study reported resolution of their symptoms and a further $9 \%$ had halved their use of PPI's. The effect was related to the volume of injection used, although repeated treatments may be necessary to gain the desired effect (33).

\section{Surgical Interventions}

Surgery can be used as either a first line treatment or in cases where medical treatments have been unsuccessful. Operative treatment may be more appropriate in cases where costs and risks of operative morbidity are low. Historically, GORD was always considered to be secondary to a hiatus hernia; therefore operations were designed purely to correct this anatomical abnormality (34) and surgery was often ineffective at treating reflux oesophagitis. However not all patients with reflux have a hiatus hernia; the mainstay of 
surgical treatment today therefore is to prevent gastric contents from refluxing into the oesophagus by recreating the natural effect of the lower oesophageal sphincter.

Indications for surgery include refractory oesophagitis after medical treatment, bleeding from the oesophageal or trans-hiatal erosions, extra-oesophageal symptoms, for example asthma or laryngitis, and patient preference (35). Surgery in patients with substantial co-morbidities (i.e cardiac or respiratory disease), impaired peristaltic function and atypical symptoms is often contra-indicated as symptoms may even be made worse by more radical treatment and, in these patients, endoscopic treatment may be more suitable. Studies have suggested that for chronic gastro-oesophageal reflux disease, surgery may be the optimal treatment (36).

In the case of the paraoesophageal hernia, the only viable treatment option is surgery. The risks of surgery associated with significant comorbidities must be weighed against the $30 \%$ lifelong risk of developing a complication of this type of hernia (7). Studies have shown that, although initially there is no significant benefit to surgical treatment for GORD, after 7 years the benefit was proven (37).

The first operative interventions for elective repair of hiatus hernia were performed in 1919 as an attempt to demonstrate the importance of herniae to the wider medical community. The original operation aimed to reduce the hernia and narrow the diaphragmatic hiatus. In 1928 a report from the Mayo Clinic described a series of 27 hiatal hernia repairs, repairing only those that were symptomatic. Early surgeons, when unable to fully close the hiatus, would suture the viscera to the abdominal wall. Concurrently, Angelo Soresi described the paralysis of the left hemi-diaphragm in difficult hernias; despite zero mortality and a low recurrence rate, the results by other surgeons performing this technique were unpredictable (34) (Is whole paragraph cited from ref. 33?). yes

In 1956, Dr. Rudolph Nissen, after years of performing various anti-reflux procedures, first performed his "gastroplication" operation, now known as the fundoplication that is in common use today. Although not gaining popularity until the 1970's, the Nissen fundoplication today has a $90 \%$ success rate (36) in resolving symptoms of GORD by altering the anatomy of the gastroesophageal junction.

The primary technique of Nissen fundoplication involves opening the phrenoesophageal ligament and dissecting the crura with preservation of the hepatic branch of the anterior vagus nerve. The lower end of the oesophagus is mobilized trans-hiatally and the short gastric vessels divided to prevent tension ("floppy-Nissen"). The crura are closed posteriorly and the stomach wrapped behind the oesophagus (38).

Other surgeons, noting the increasing incidence of dysphagia after the Nissen fundoplication, described modifications to this procedure; Toupet performed a 270-degree posterior wrap in 1963 with no division of the short gastric vessels. Dor developed an anterior hiatal 180-200 degree wrap (1962). The Lind (subtotal 270-300 degree lateral wrap) is another modification that is frequently used technique in our unit (39).

The technique used is important, not only in terms of success but also in complication rate. Laparoscopic Nissen and Toupet have similar outcomes (40), and no difference between the Lind and the Nissen has been demonstrated at one year (41). Nine randomized controlled trials have compared the Toupet fundoplication with the Nissen (41-53). Most studies have demonstrated that the Toupet fundoplication has a lower postoperative incidence of dysphagia with no difference in level of reflux. However, none of these trials have more than a five-year follow up, and other studies suggest that the Toupet has inferior long-term results when compared to the Nissen $(53,54)$. The Nissen fundoplication itself has in the past shown a $10-40 \%$ risk of short-term dysphagia and 5-10\% long term, and so patients with a pre-operative oesophageal motility disorder may be at a slightly increased risk of post-operative complications (55). Conversely, in our experience, many patients with preoperative motility disorders find that the decrease in acidic irritation causes a degree of motility that improves their symptoms. Although there is no universally accepted definition of disordered oesophageal motility, it has been defined by many as less than $80 \%$ propagation of primary peristalsis or distal oesophageal contraction of less than $30 \mathrm{mmHg}(55,56)$. It has been hypothesized that despite the reported incidence of post-operative dysphagia in the Nissen fundoplication, there seems to be no benefit in using a partial wrap instead of the 360-degree in patients with disordered motility (56).

The anterior wrap technique, although shown to decrease the incidence of postoperative dysphagia with a follow up of 10 years (57), has a higher incidence of failure to control reflux and the need for further anti-reflux surgery when compared to the Nissen operation. Furthermore, when compared to the Toupet fundoplication, the anterior wraps are found to be inferior in terms of both incidence of dysphagia and reflux $(53,58)$. This same study concluded that anterior wraps cannot be recommended due to insufficient reflux control. Although the wrap technique has been shown to be influential, anterior versus posterior repair of the hiatus itself has not been shown to affect outcome (38).

The classic Nissen fundoplication is the only version in which the short gastrics are divided: no difference in successful outcome has been shown in patients with or without division of these blood vessels (31, 59-62), although studies have shown an increase in operating time, epigastric bloating and flatus due to an inability to expel air from the stomach (61-63). Some authors claim that division of the short gastric vessels is necessary where the wrap would otherwise be under tension; others dispute this and believe that short gastric division is never necessary (31).

Excellent results for both the trans-thoracic and trans-abdominal approach in open surgery for anti-reflux surgery have been reported, and the approach unsurprisingly, is often based on the subspecialty of the surgeon. 
Trans-abdominal operations are more common in General Surgery; thoracic surgeons have published trans-thoracic series. A review of the literature published in 2008 demonstrated a superior ability to mobilise the oesophagus trans-thoracically and therefore may be more suitable if performing a Collis-Nissen operation for a shortened oesophagus. Interestingly, short oesophagus is reported in $69-97 \%$ of thoracic operations thereby necessitating a Collis-Nissen gastroplasty; however this finding is rare during the transabdominal operation and the oesophagus rarely needs extensive mobilisation (64). The abdominal approach avoids the need for the painful thoracotomy incision therefore posing fewer respiratory considerations; as there are fewer Collis gastroplasties performed, an anastomosis and its considerable complication risks are avoided. The Collis Nissen fundoplication involves mobilization of the whole oesophagus with division of the short gastrics, and creation of a neo-oesophagus from the fundus of the stomach, thereby lengthening the oesophagus, before performing the Nissen fundoplication wrap.

Traditional anti-reflux was performed at open surgery. However during the advancement of laparoscopic surgery over the last 20 years, unless contraindicated, most surgery is performed laparoscopically. The first laparoscopic anti-reflux operation was performed as the Nissen fundoplication in $1991(65,66)$. Since then, numerous studies including randomized control trials have been published since 1997, comparing traditional open surgery with laparoscopic techniques, and the results for laparoscopy are favorable in terms of long term outcome, costs and recovery period $(36,38,67-71)$. Only one study has been published showing unfavorable results in laparoscopic surgery demonstrating an increased incidence of dysphagia at 3 month follow up (72).

Other less common anti-reflux surgical techniques include repairing the defect in the oesophageal hiatus with a mesh after reducing the hernia, without performing a fundoplication. During fundoplication, sutures are placed between the diaphragmatic crura in order to decrease the size of the hiatal defect but this procedure can be performed without the wrap. The first mesh repair of the crura was performed in 1993 by placing a polyester mesh anterior to the oesophagus (56). This series included 6 patients in whom the defect was too large to close primarily, and the short-term results were favourable. Numerous trials have demonstrated low recurrence rates in patients undergoing mesh hiatoplasty compared to those undergoing primary repair (73-75). Dysphagia rates in the short term were found to be higher in mesh repairs, although long-term results equate those of the non-mesh repairs (64).

Although surgery is successful in the treatment of GORD, recurrence remains possible. Recurrence rates of $9-30 \%$ at open surgery and $2-17 \%$ at laparoscopic surgery have been reported (76-80). Five causes of operative fundoplication failure have been described: slipped or misplaced fundoplication, disrupted, twisted or herniated fundoplication and an excessively tight or lengthy wrap. In some cases, the original pathology may have been misdiagnosed. Fewer adhesions are formed at laparoscopic operation and this may contribute to the recurrence rate, although given that recurrence is lower than at open operation, this may not be a factor. Broeders et al demonstrated that patients who had significantly reduced oesophageal peristalsis pre-operatively may be more at risk of failure (81); in their series, $14 \%$ of post operative patients had persistent pathological acid exposure. $50 \%$ of these patients underwent revisional surgery for symptomatic recurrence; a further 8 patients underwent surgery for persistent dysphagia and 2 for intra-thoracic herniation of the wrap. Randomised controlled trails have demonstrated that approximately $9.5 \%$ of patients need revisional anti-reflux surgery (82). Attempts have been made to predict the likelihood of failure: the presence of disordered motility, and excessive supine acid exposure preoperatively has been shown to be predictive of recurrence. Age, sex, and body mass index (BMI) have been shown in some studies to predict recurrence $(83,84)$ but not by others, and hiatal hernia size seems to have no bearing (83). In one case, a sleeve gastrectomy was performed as a revision operation for an obese patient with a complex recurrent paraoesophageal hernia (85).

There is a known association between obesity and GORD, and higher failure rates have been demonstrated in patients with a BMI of over 30, $(86,87)$. The laparoscopic Roux-en-Y bypass is an effective technique for the management of morbid obesity, but has the advantageous effect of reducing and controlling GORD. The American Society of Gastroenterologists recommend that patients with a BMI of over 35 should undergo primary bypass for control of reflux rather than fundoplication. Although gastric banding may also decrease the incidence of reflux, a consensus has not yet been reached therefore bypass should be considered first, despite it's increased technical requirements $(88,89)$. Obesity is playing an increasing role in the aetiology of GORD and as the obesity epidemic worsens other approaches to treatment will need to be adopted.

\section{Conclusion}

A conclusion is needed at the end of the article.

A variety of treatment modalities exist for the management of gastro-oesophageal reflux disease, ranging from simple lifestyle modification to surgical treatment. Where a hiatus hernia co-exists alongside with reflux disease, primary repair could be considered a reasonable first line treatment. In the case of para-oesophageal hiatus hernia, operative intervention is imperative given the risk of complications. The clinician should be aware of the spectrum of reflux disease, and causes, in order to help the patient make an informed choice regarding their treatment. 


\section{References}

[1] Dent J, El-Serag HB, Wallander MA, Johansson S. Epidemiology of gastro-oesophageal reflux disease: a systematic review. Gut. 2005;54(5):710-7.

[2] NICE. Dyspepsia: managing adults in primary care. April 2006 Contract No.: 4.

[3] Dodds WJ, Dent J, Hogan WJ, Helm JF, Hauser R, Patel GK, et al. Mechanisms of gastroesophageal reflux in patients with reflux esophagitis. N Engl J Med. 1982;307(25):1547-52.

[4] Friedenberg FK, Xanthopoulos M, Foster GD, Richter JE. The association between gastroesophageal reflux disease and obesity. Am J Gastroenterol. 2008;103(8):2111-22.

[5] El-Serag H. Role of obesity in GORD-related disorders. Gut. 2008;57(3):281-4.

[6] Kaltenbach T, Crockett S, Gerson LB. Are lifestyle measures effective in patients with gastroesophageal reflux disease? An evidence-based approach. Arch Intern Med. 2006;166(9):965-71.

[7] Bland K. Paraesophageal hiatus hernias. Limited S-VL, editor. Surgery of the esophagus and stomach 2011.

[8] Ronkainen J, Aro P, Storskrubb T, Johansson SE, Lind T, Bolling-Sternevald E, et al. Prevalence of Barrett's esophagus in the general population: an endoscopic study. Gastroenterology. 2005;129(6):1825-31.

[9] Cameron AJ. Epidemiology of Barrett's esophagus and adenocarcinoma. Dis Esophagus. 2002;15(2):106-8.

[10] Marano S, Mattacchione S, Paltrinieri G, Palombi L, Mingarelli V, Tosato F. A three-year experience of the Referral Center for Surgical Treatment of Gastroesophageal Reflux Disease. Minerva Chir. 2011;66(2):77-85.

[11] Murray L, Watson P, Johnston B, Sloan J, Mainie IM, Gavin A. Risk of adenocarcinoma in Barrett's oesophagus: population based study. BMJ. 2003;327(7414):534-5.

[12] C H. Massive incarcerated Hiatus Hernia. Churchill Livingstone NY, editor. Esophageal surgery 1995.

[13] Smith A, Dickerman R, McGuire C, JW E, McConathy W, HF P. Pressure-overload-induced sliding hiatal hernia in power athletes. J Clin Gastroenterol. ; 1999. p. 352-4.

[14] Nagaya M, Akatsuka H, Kato J. Gastroesophageal reflux occuring after repair of congenital diaphragmatic hernia. Journal of Pediatric Surgery. 1994;29(11):1447-51.

[15] Gordon C, Kang JY, Neild PJ, Maxwell JD. The role of the hiatus hernia in gastro-oesophageal reflux disease. Aliment Pharmacol Ther. 2004;20(7):719-32.

[16] Stanciu C, Bennett JR. Smoking and gastro-oesophageal reflux. Br Med J. 1972;3(5830):793-5.

[17] Nocon M, Labenz J, Willich SN. Lifestyle factors and symptoms of gastro-oesophageal reflux -- a population-based study. Aliment Pharmacol Ther. 2006;23(1):169-74.

[18] Anderson LA, Cantwell MM, Watson RG, Johnston BT, Murphy SJ, Ferguson HR, et al. The association between alcohol and reflux esophagitis, Barrett's esophagus, and esophageal adenocarcinoma. Gastroenterology. 2009;136(3):799-805.
[19] Tack J, Sifrim D. Anti-relaxation therapy in GORD. Gut. 2002;50(1):6-7.

[20] Bradshaw J, Brittain RT, Clitherow JW, Daly MJ, Jack D, Price BJ, et al. Ranitidine (AH 19065): a new potent, selective histamine $\mathrm{H} 2$-receptor antagonist [proceedings]. $\mathrm{Br}$ J Pharmacol. 1979;66(3):464P.

[21] Venables TL, Newland RD, Patel AC, Hole J, Wilcock C, Turbitt ML. Omeprazole 10 milligrams once daily, omeprazole 20 milligrams once daily, or ranitidine 150 milligrams twice daily, evaluated as initial therapy for the relief of symptoms of gastro-oesophageal reflux disease in general practice. Scand J Gastroenterol. 1997;32(10):965-73.

[22] Forgacs I, Loganayagam A. Overprescribing proton pump inhibitors. BMJ. 2008;336(7634):2-3.

[23] Gough AL, Long RG, Cooper BT, Fosters CS, Garrett AD, Langworthy $\mathrm{CH}$. Lansoprazole versus ranitidine in the maintenance treatment of reflux oesophagitis. Aliment Pharmacol Ther. 1996;10(4):529-39.

[24] Parsonnet J, Friedman GD, Vandersteen DP, Chang Y, Vogelman $\mathrm{JH}$, Orentreich $\mathrm{N}$, et al. Helicobacter pylori infection and the risk of gastric carcinoma. N Engl J Med. 1991;325(16):1127-31.

[25] Scarpa M, Angriman I, Prando D, Polese L, Ruffolo C, Pilon F, et al. Helicobacter pylori and gastroesophageal reflux disease: a cross sectional study. Hepatogastroenterology. 2011;58(105):69-75.

[26] Peek RM, Blaser MJ. Helicobacter pylori and gastrointestinal tract adenocarcinomas. Nat Rev Cancer. 2002;2(1):28-37.

[27] Raghunath A, Hungin AP, Wooff D, Childs S. Prevalence of Helicobacter pylori in patients with gastro-oesophageal reflux disease: systematic review. BMJ. 2003;326(7392):737.

[28] Chourasia D, Misra A, Tripathi S, Krishnani N, Ghoshal UC. Patients with Helicobacter pylori infection have less severe gastroesophageal reflux disease: a study using endoscopy, 24-hour gastric and esophageal $\mathrm{pH}$ metry. Indian J Gastroenterol. 2011;30(1):12-21.

[29] Yeh RW, Triadafilopoulos G. Endoscopic antireflux therapy: the Stretta procedure. Thorac Surg Clin. 2005;15(3):395-403.

[30] Torquati A, Houston HL, Kaiser J, Holzman MD, Richards WO. Long-term follow-up study of the Stretta procedure for the treatment of gastroesophageal reflux disease. Surg Endosc. 2004;18(10):1475-9.

[31] O'Boyle CJ, Watson DI, Jamieson GG, Myers JC, Game PA, Devitt PG. Division of short gastric vessels at laparoscopic nissen fundoplication: a prospective double-blind randomized trial with 5-year follow-up. Ann Surg. 2002;235(2):165-70.

[32] Chen YK, Raijman I, Ben-Menachem T, Starpoli AA, Liu J, Pazwash $\mathrm{H}$, et al. Long-term outcomes of endoluminal gastroplication: a U.S. multicenter trial. Gastrointest Endosc. 2005;61(6):659-67.

[33] NICE. Endoscopic injection of bulking agents for gastro-oesophageal reflux disease. 2004.

[34] Stylopoulos N, Rattner DW. The history of hiatal hernia surgery: from Bowditch to laparoscopy. Ann Surg. 2005;241(1):185-93. 
[35] Spechler SJ, Lee E, Ahnen D, Goyal RK, Hirano I, Ramirez F, et al. Long-term outcome of medical and surgical therapies for gastroesophageal reflux disease: follow-up of a randomized controlled trial. JAMA. 2001;285(18):2331-8.

[36] Ackroyd R, Watson DI, Majeed AW, Troy G, Treacy PJ, Stoddard CJ. Randomized clinical trial of laparoscopic versus open fundoplication for gastro-oesophageal reflux disease. Br J Surg. 2004;91(8):975-82.

[37] Lundell L, Miettinen P, Myrvold HE, Hatlebakk JG, Wallin L, Malm A, et al. Seven-year follow-up of a randomized clinical trial comparing proton-pump inhibition with surgical therapy for reflux oesophagitis. Br J Surg. 2007;94(2):198-203.

[38] Watson DI, Jamieson GG, Devitt PG, Kennedy JA, Ellis T, Ackroyd R, et al. A prospective randomized trial of laparoscopic Nissen fundoplication with anterior vs posterior hiatal repair. Arch Surg. 2001;136(7):745-51.

[39] Cameron I, Stoddard J, Treacy P, Patterson J, Stoddard C. Long-term symptomatic follow up after Lind fundoplication. Br J Surg. 2000;87(3):362-73.

[40] Shaw JM, Bornman PC, Callanan MD, Beckingham IJ, Metz DC. Long-term outcome of laparoscopic Nissen and laparoscopic Toupet fundoplication for gastroesophageal reflux disease: a prospective, randomized trial. Surg Endosc. 2010;24(4):924-32.

[41] Fibbe C, Layer P, Keller J, Strate U, Emmermann A, Zornig C. Esophageal motility in reflux disease before and after fundoplication: a prospective, randomized, clinical, and manometric study. Gastroenterology. 2001;121(1):5-14.

[42] Chrysos E, Tsiaoussis J, Zoras OJ, Athanasakis E, Mantides A, Katsamouris A, et al. Laparoscopic surgery for gastroesophageal reflux disease patients with impaired esophageal peristalsis: total or partial fundoplication? J Am Coll Surg. 2003;197(1):8-15.

[43] Hagedorn C, Lönroth H, Rydberg L, Ruth M, Lundell L. Long-term efficacy of total (Nissen-Rossetti) and posterior partial (Toupet) fundoplication: results of a randomized clinical trial. J Gastrointest Surg. 2002;6(4):540-5.

[44] Lundell L, Abrahamsson H, Ruth M, Sandberg N, Olbe LC. Lower esophageal sphincter characteristics and esophageal acid exposure following partial or 360 degrees fundoplication: results of a prospective, randomized, clinical study. World J Surg. 1991;15(1):115-20; discussion 21.

[45] Segol P, Hay JM, Pottier D. [Surgical treatment of gastroesophageal reflux: which operation to choose: Nissen, Toupet or Lortat-Jacob? A multicenter randomized trial]. Gastroenterol Clin Biol. 1989;13(11):873-9.

[46] Thor KB, Silander T. A long-term randomized prospective trial of the Nissen procedure versus a modified Toupet technique. Ann Surg. 1989;210(6):719-24.

[47] Zornig C, Strate U, Fibbe C, Emmermann A, Layer P. Nissen vs Toupet laparoscopic fundoplication. Surg Endosc. 2002;16(5):758-66.

[48] Lundell L, Abrahamsson H, Ruth M, Rydberg L, Lönroth H, Olbe L. Long-term results of a prospective randomized comparison of total fundic wrap (Nissen-Rossetti) or semifundoplication (Toupet) for gastro-oesophageal reflux. Br J Surg. 1996;83(6):830-5.
[49] Strate U, Emmermann A, Fibbe C, Layer P, Zornig C. Laparoscopic fundoplication: Nissen versus Toupet two-year outcome of a prospective randomized study of 200 patients regarding preoperative esophageal motility. Surg Endosc. 2008;22(1):21-30.

[50] Booth MI, Stratford J, Jones L, Dehn TC. Randomized clinical trial of laparoscopic total (Nissen) versus posterior partial (Toupet) fundoplication for gastro-oesophageal reflux disease based on preoperative oesophageal manometry. Br J Surg. 2008;95(1):57-63.

[51] Mickevicius A, Endzinas Z, Kiudelis M, Jonaitis L, Kupcinskas L, Maleckas A, et al. Influence of wrap length on the effectiveness of Nissen and Toupet fundoplication: a prospective randomized study. Surg Endosc. 2008;22(10):2269-76.

[52] Guérin E, Bétroune K, Closset J, Mehdi A, Lefèbvre JC, Houben JJ, et al. Nissen versus Toupet fundoplication: results of a randomized and multicenter trial. Surg Endosc. 2007;21(11):1985-90.

[53] Jobe BA, Wallace J, Hansen PD, Swanstrom LL. Evaluation of laparoscopic Toupet fundoplication as a primary repair for all patients with medically resistant gastroesophageal reflux. Surg Endosc. 1997;11(11):1080-3.

[54] Patti MG, Robinson T, Galvani C, Gorodner MV, Fisichella PM, Way LW. Total fundoplication is superior to partial fundoplication even when esophageal peristalsis is weak. $\mathrm{J}$ Am Coll Surg. 2004;198(6):863-9; discussion 9-70.

[55] Khan M, Smythe A, Globe J, Stoddard C, Ackroyd R. Randomized controlled trial oflaparoscopic anterior versus posterior fundoplication for gastro-oesophageal reflux disease. ANZ J Surg. 2010;80(7-8):500-5.

[56] Rydberg L, Ruth M, Abrahamsson H, Lundell L. Tailoring antireflux surgery: A randomized clinical trial. World J Surg. 1999;23(6):612-8.

[57] Cai W, Watson DI, Lally CJ, Devitt PG, Game PA, Jamieson GG. Ten-year clinical outcome of a prospective randomized clinical trial of laparoscopic Nissen versus anterior 180( degrees ) partial fundoplication. $\mathrm{Br} \mathrm{J}$ Surg. 2008;95(12):1501-5.

[58] Engström C, Lönroth H, Mardani J, Lundell L. An anterior or posterior approach to partial fundoplication? Long-term results of a randomized trial. World J Surg. 2007;31(6):1221-5; discussion 6-7.

[59] Yang H, Watson DI, Lally CJ, Devitt PG, Game PA, Jamieson GG. Randomized trial of division versus nondivision of the short gastric vessels during laparoscopic Nissen fundoplication: 10-year outcomes. Ann Surg. 2008;247(1):38-42.

[60] Engström C, Blomqvist A, Dalenbäck J, Lönroth H, Ruth M, Lundell L. Mechanical consequences of short gastric vessel division at the time of laparoscopic total fundoplication. J Gastrointest Surg. 2004;8(4):442-7.

[61] Blomqvist A, Dalenbäck J, Hagedorn C, Lönroth H, Hyltander A, Lundell L. Impact of complete gastric fundus mobilization on outcome after laparoscopic total fundoplication. J Gastrointest Surg. 2000;4(5):493-500.

[62] Chrysos E, Tzortzinis A, Tsiaoussis J, Athanasakis H, Vasssilakis J, Xynos E. Prospective randomized trial 
comparing Nissen to Nissen-Rossetti technique for laparoscopic fundoplication. Am J Surg. 2001;182(3):215-21

[63] Gad El-Hak N, Abo Zied M, Aboelenen A, Fouad A, Abd Alla T, El-Shoubary M, et al. Short gastric vessels division in Laparoscopic Nissen Fundoplication. Hepatogastroenterology. 2005;52(66):1742-7.

[64] Davis SS. Current controversies in paraesophageal hernia repair. Surg Clin North Am. 2008;88(5):959-78, vi.

[65] Geagea T. Laparoscopic Nissen's fundoplication: preliminary report on ten cases. Surg Endosc. 1991;5(4):170-3.

[66] Dallemagne B, Weerts JM, Jehaes C, Markiewicz S, Lombard R. Laparoscopic Nissen fundoplication: preliminary report. Surg Laparosc Endosc. 1991;1(3):138-43.

[67] Perttilä J, Salo M, Ovaska J, Grönroos J, Lavonius M, Katila $\mathrm{A}$, et al. Immune response after laparoscopic and conventional Nissen fundoplication. Eur $\mathrm{J}$ Surg. 1999;165(1):21-8.

[68] Heikkinen TJ, Haukipuro K, Bringman S, Ramel S, Sorasto A, Hulkko A. Comparison of laparoscopic and open Nissen fundoplication 2 years after operation. A prospective randomized trial. Surg Endosc. 2000;14(11):1019-23.

[69] Nilsson G, Larsson S, Johnsson F. Randomized clinical trial of laparoscopic versus open fundoplication: blind evaluation of recovery and discharge period. $\mathrm{Br} \mathrm{J}$ Surg. 2000;87(7):873-8.

[70] Chrysos E, Tsiaoussis J, Athanasakis E, Zoras O, Vassilakis JS, Xynos E. Laparoscopic vs open approach for Nissen fundoplication. A comparative study. Surg Endosc. 2002;16(12):1679-84.

[71] Salminen PT, Hiekkanen HI, Rantala AP, Ovaska JT. Comparison of long-term outcome of laparoscopic and conventional nissen fundoplication: a prospective randomized study with an 11-year follow-up. Ann Surg. 2007;246(2):201-6.

[72] Bais JE, Bartelsman JF, Bonjer HJ, Cuesta MA, Go PM, Klinkenberg-Knol EC, et al. Laparoscopic or conventional Nissen fundoplication for gastro-oesophageal reflux disease: randomised clinical trial. The Netherlands Antireflux Surgery Study Group. Lancet. 2000;355(9199):170-4.

[73] Frantzides CT, Madan AK, Carlson MA, Stavropoulos GP. A prospective, randomized trial of laparoscopic polytetrafluoroethylene (PTFE) patch repair vs simple cruroplasty for large hiatal hernia. Arch Surg. 2002;137(6):649-52.

[74] Carlson MA, Richards CG, Frantzides CT. Laparoscopic prosthetic reinforcement of hiatal herniorrhaphy. Dig Surg. 1999;16(5):407-10.

[75] Frantzides CT, Richards CG, Carlson MA. Laparoscopic repair of large hiatal hernia with polytetrafluoroethylene. Surg Endosc. 1999;13(9):906-8.
[76] Hinder RA, Filipi CJ, Wetscher G, Neary P, DeMeester TR, Perdikis G. Laparoscopic Nissen fundoplication is an effective treatment for gastroesophageal reflux disease. Ann Surg. 1994;220(4):472-81; discussion 81-3.

[77] Hunter JG, Trus TL, Branum GD, Waring JP, Wood WC. A physiologic approach to laparoscopic fundoplication for gastroesophageal reflux disease. Ann Surg. 1996;223(6):673-85; discussion 85-7.

[78] Peters JH, Heimbucher J, Kauer WK, Incarbone R, Bremner CG, DeMeester TR. Clinical and physiologic comparison of laparoscopic and open Nissen fundoplication. J Am Coll Surg. 1995;180(4):385-93.

[79] Jamieson GG, Watson DI, Britten-Jones R, Mitchell PC, Anvari M. Laparoscopic Nissen fundoplication. Ann Surg. 1994;220(2):137-45.

[80] Cuschieri A, Hunter J, Wolfe B, Swanstrom LL, Hutson W. Multicenter prospective evaluation of laparoscopic antireflux surgery. Preliminary report. Surg Endosc. 1993;7(6):505-10.

[81] Broeders JA, Roks DJ, Draaisma WA, Vlek AL, Hazebroek EJ, Broeders IA, et al. Predictors of objectively identified recurrent reflux after primary Nissen fundoplication. Br J Surg. 2011;98(5):673-9.

[82] Catarci M, Gentileschi P, Papi C, Carrara A, Marrese R, Gaspari AL, et al. Evidence-based appraisal of antireflux fundoplication. Ann Surg. 2004;239(3):325-37.

[83] Oelschlager BK, Quiroga E, Parra JD, Cahill M, Polissar N, Pellegrini CA. Long-term outcomes after laparoscopic antireflux surgery. Am J Gastroenterol. 2008;103(2):280-7; quiz 8.

[84] Beck PE, Watson DI, Devitt PG, Game PA, Jamieson GG. Impact of gender and age on the long-term outcome of laparoscopic fundoplication. World J Surg. 2009;33(12):2620-6.

[85] Cuenca-Abente F, Parra JD, Oelschlager BK. Laparoscopic sleeve gastrectomy: an alternative for recurrent paraesophageal hernias in obese patients. JSLS. 2006;10(1):86-9.

[86] Morgenthal CB, Lin E, Shane MD, Hunter JG, Smith CD. Who will fail laparoscopic Nissen fundoplication? Preoperative prediction of long-term outcomes. Surg Endosc. 2007;21(11):1978-84.

[87] Perez AR, Moncure AC, Rattner DW. Obesity adversely affects the outcome of antireflux operations. Surg Endosc. 2001;15(9):986-9.

[88] Gutschow CA, Collet P, Prenzel K, Hölscher AH, Schneider PM. Long-term results and gastroesophageal reflux in a series of laparoscopic adjustable gastric banding. J Gastrointest Surg. 2005;9(7):941-8.

[89] Tolonen P, Victorzon M, Niemi R, Mäkelä J. Does gastric banding for morbid obesity reduce or increase gastroesophageal reflux? Obes Surg. 2006;16(11):1469-74. 